\title{
THE IMPACT OF COVID-19 ON AIRWAY MANAGEMENT IN PREHOSPITAL RESUSCITATION
}

\author{
Kecskés Attila ${ }^{1} \odot$, Kobi Ludwin ${ }^{2} \odot$, Togay Evrin ${ }^{3} \odot$, Burak Katipoğlu ${ }^{3} \odot$, \\ Tomasz Torlinski ${ }^{4} \oplus$, Michal Pruc ${ }^{2} \odot$, Lukasz Szarpak ${ }^{2,5,6} \odot$
}

\author{
${ }^{1}$ NATO Centre of Excellence for Military Medicine, Budapest, Hungary \\ ${ }^{2}$ Polish Society of Disaster Medicine, Warsaw, Poland \\ ${ }^{3}$ Department of Emergency Medicine, Ufuk University Medical Faculty, Dr Ridvan Ege Education and Research Hospital, Ankara, Turkey \\ ${ }^{4}$ Department of Anaesthetics and Intensive Care Medicine, Queen Elizabeth Hospital Birmingham, University Hospitals Birmingham, UK \\ ${ }^{5}$ Maria Sklodowska-Curie Medical Academy in Warsaw, Poland \\ ${ }^{6}$ Maria Sklodowska-Curie Bialystok Oncology Centre, Bialystok, Poland
}

KEY WORDS: COVID-19, SARS-CoV-2, airway management, endotracheal intubation, supraglottic airway device, prehospital, resuscitation, OHCA

Disaster Emerg Med J 2020; 5(4)

Since the end of 2019, the world has been struggling with the SARS-CoV-2 virus and the COVID-19 disease it causes. According to the Johns Hopkins University of Medicine, 55.333.374 people have now been infected and the death rate from COVID-19 is $2.4 \%$. However, as shown by studies including Chen et al. [1] and Borkowska M. [2], the effectiveness of cardiopulmonary resuscitation, especially in the aspect of out-of-hospital cardiac arrest, is insufficient and lower than it was before the pandemic. One of the key elements of cardiopulmonary resuscitation is securing the airway potency and implementing respiratory support $[3,4]$. However, as shown by many studies, the performance of medical procedures in personal protective equipment for aerosol-generating procedures (PPE AGP) is difficult and often requires a much longer time than it would have been in normal conditions without PPE AGP [5]. Guidelines for CPR recommend minimizing interruptions in chest compressions to increase the effectiveness of CPR. For this purpose, the respiratory tract should be secured with an endotracheal tube or with epiglotting ventilation devices.

This meta-analysis was conducted using the Preferred Reporting Items for Systematic Reviews and Meta-Analysis (PRISMA) guidelines and reported in accordance with the Meta-analysis Of Observational Studies in Epidemiology (MOOSE) statement. Three authors (LS, KL and MP) searched electronic resourc- es (Medline, Medline in process, Embase, Cochrane Library for clinical trials, PubMed, Web of Science, SCOPUS) from databases inception to November 12, 2020, using the query: 'airway management' or 'endotracheal intubation' or 'intubation' or 'ETI' or 'supraglottic airway device*' or 'SAD"' and 'cardiopulmonary resuscitation' or 'CPR' or 'out-of-hospital cardiac arrest' or 'OHCA' and 'COVID-19' or 'SARS-CoV-2' or 'coronavirus'.

Systematic review and meta-analysis were performed to assess the impact of the COVID-19 pandemic on the method of securing the potency of the respiratory tract during resuscitation. Finally, four studies including 27.330 patients were included [6-9]. Four studies showed the frequency of intubation use in COVID-19 and pre-COVID-19 periods. Polled analysis show intubation rate in COVID-19 and pre-COVID-19 periods varied and occurred to $47.4 \%$ vs. $43.8 \%(\mathrm{OR}=0.53 ; 95 \% \mathrm{Cl}: 0.33,0.85$; $\mathrm{p}=0.008$; Fig. 1). In the case of SADs, the frequency of using this form of airway protection during COVID-19 period was $26.9 \%$ compared with $7.3 \%$ for the non-COVID-19 period (OR $=2.38 ; 95 \%$ Cl: $1.74,3.25 ; p<0.001)$.

In conclusion, the meta-analysis carried out showed the pandemic caused that advanced airway management is used statistically significantly more often during out-of-hospital cardiac arrests. EMS 


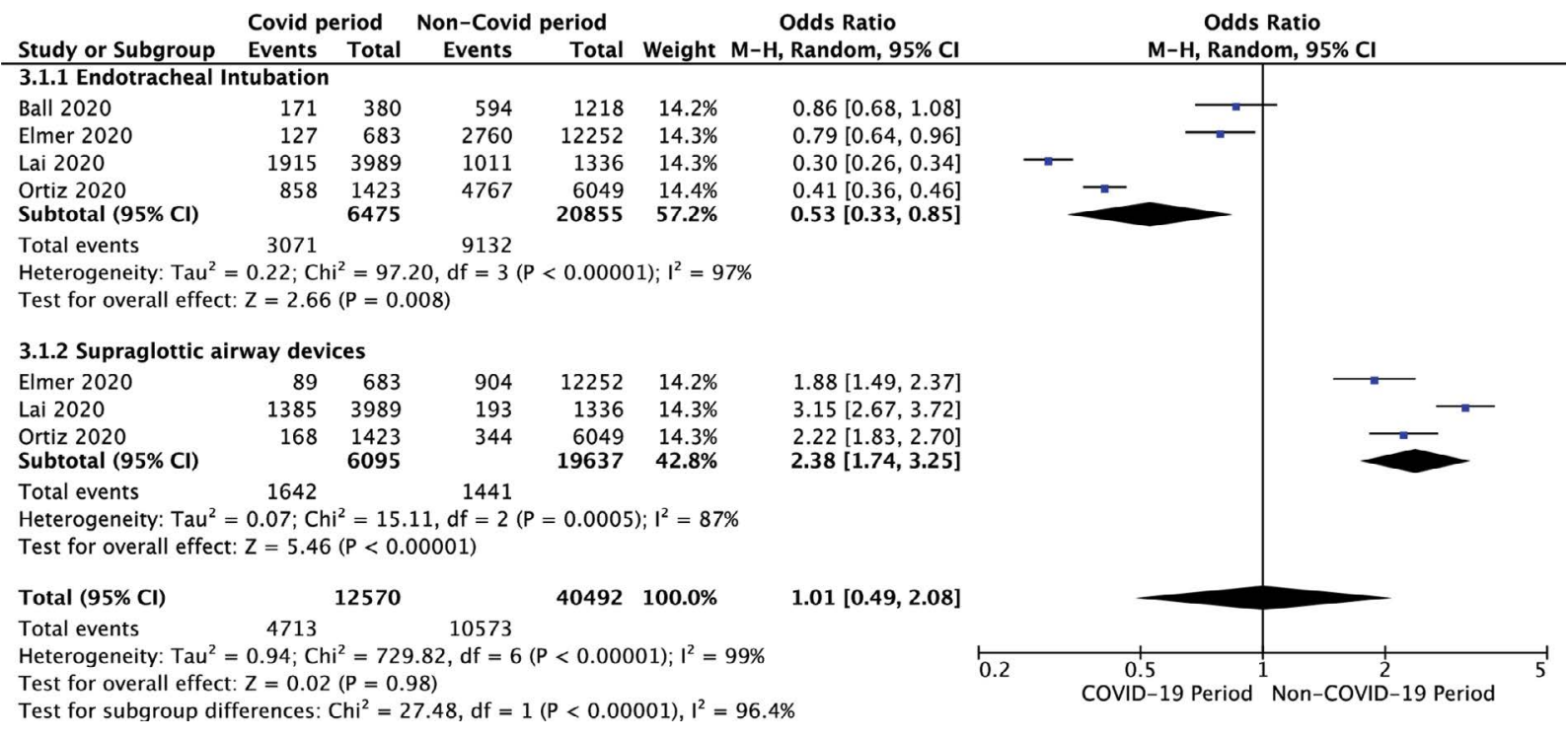

FIGURE 1. Forest plot of airway management methods in COVID-19 vs. non-COVID-19 periods. The centre of each square represents the weighted odds ratios for individual trials, and the corresponding horizontal line stands for a $95 \%$ confidence interval. The diamonds represent pooled results

staff uses endotracheal intubation less than twice as often as supraglottic airway devices.

Funding: None.

Conflict of interest: The authors declare that they have no conflict of interest.

\section{REFERENCES}

1. Chan PS, Girotra S, Tang Y, et al. Outcomes for Out-of-Hospital Cardiac Arrest in the United States During the Coronavirus Disease 2019 Pandemic. JAMA Cardiol. 2020 [Epub ahead of print], doi: 10.1001/ jamacardio.2020.6210, indexed in Pubmed: 33188678.

2. Borkowska MJ, Smereka J, Safiejko K, et al. Out-of-hospital cardiac arrest treated by emergency medical service teams during COVID-19 pandemic: A retrospective cohort study. Cardiol J. 2020 [Epub ahead of print], doi: 10.5603/CJ.a2020.0135, indexed in Pubmed: 33140396.

3. Madziala M. Supraglottic airway devices as a method of airway management in prehospital setting. Disaster and Emergency Medicine Journal. 2019; 4(1): 29-30, doi: 10.5603/demj.2019.0006.

4. Ludwin K, Bialka S, Czyzewski L, et al. Video laryngoscopy for endotracheal intubation of adult patients with suspected/ confirmed COVID-19. A systematic review and meta-analysis of randomized controlled trials. Disaster and Emergency Medicine Journal. 2020, doi: 10.5603/demj.a2020.0023.

5. Malysz M, Jaguszewski M, Szarpak L, et al. Comparison of different chest compression positions for use while wearing CBRN-PPE: a randomized crossover simulation trial. Disaster and Emergency Medicine Journal. 2020, doi: 10.5603/demj.a2020.0034.

6. Ball J, Nehme Z, Bernard S, et al. Collateral damage: Hidden impact of the COVID-19 pandemic on the out-of-hospital cardiac arrest system-of-care. Resuscitation. 2020; 156: 157-163, doi: 10.1016/j. resuscitation.2020.09.017, indexed in Pubmed: 32961304.

7. Elmer J, Okubo M, Guyette FX, et al. Indirect effects of COVID-19 on OHCA in a low prevalence region. Resuscitation. 2020; 156: 282-283, doi: 10.1016/j.resuscitation.2020.08.127, indexed in Pubmed: 32920116.

8. Lai PH, Lancet EA, Weiden MD, et al. Characteristics Associated With Out-of-Hospital Cardiac Arrests and Resuscitations During the Novel Coronavirus Disease 2019 Pandemic in New York City. JAMA Cardiol. 2020 [Epub ahead of print], doi: 10.1001/jamacardio.2020.2488, indexed in Pubmed: 32558876.

9. Rosell Ortiz F, Fernández Del Valle P, Knox EC, et al. OHSCAR investigators. Influence of the Covid-19 pandemic on out-of-hospital cardiac arrest. A Spanish nationwide prospective cohort study. Resuscitation. 2020 [Epub ahead of print], doi: 10.1016/j.resuscitation.2020.09.037, indexed in Pubmed: 33049385. 